\title{
Ants Acquire the Notion of Zero through Experiences
}

\author{
Marie-Claire Cammaerts ${ }^{1} \&$ Roger Cammaerts ${ }^{2}$ \\ ${ }^{1}$ Independent Researcher, Retired from the Biology of Organisms Department, University of Brussels, Belgium \\ ${ }^{2}$ Independent Researcher, Retired from the Natural and Agricultural Environmental Studies Department \\ (DEMNA) of the Walloon Region, Belgium \\ Correspondence: Marie-Claire Cammaerts, Independent Researcher, 27, Square du Castel Fleuri, 1170 Bruxelles, \\ Belgium. Tel: 32-2-673-49-69. E-mail: mccammaerts@gmail.com
}

Received: December 30, 2019

Accepted: January 12, 2019

Online Published: January 16, 2020

doi:10.5539/ijb.v12n2p13

URL: https://doi.org/10.5539/ijb.v12n2p13

\begin{abstract}
The workers of the ant Myrmica sabuleti have a concrete notion of zero and locate this zero at the lower end of their mental number line. Here we examined how they acquire such a notion: do they have it natively or do they learn it over their life? We worked on young ants a few weeks old, and used operant conditioning to zero, the latter being a white paper or 'nothing, no cue', presented $v s$ a black dot. In a first series of experiments, we showed that young ants do not detain the notion of zero. In a second series of experiments on the same ants, we first tempted learning them the notion of zero by facing them with a filled and an empty food tube during two days. They were then submitted to conditioning to 'zero', and they correctly responded to it. Consequently, the ants have not natively the notion of zero but acquire it through experiences.
\end{abstract}

Keywords: Learning, Myrmica sabuleti, Operant Conditioning, Ontogenesis, Young individuals

\section{Introduction}

The workers of the ant Myrmica sabuleti Meinert 1861 have the notion of zero on the basis of visual and olfactory elements and locate the zero at its due cardinal place, at the start of an increasing series of elements as well as at the end of a decreasing series of elements (Cammaerts \& Cammaerts, 2019a, b, c). The experiments made for showing these abilities were conducted on foragers, i.e. on ants two to three years old. It remained to examine if ants possess the notion of zero very early after their emergence from the nymphal stage, i.e. natively, or if they acquire this notion progressively in the course of their life. We thus undertook experiments on colonies made of only young ants, these colonies having been just previously used for examining if they had already a mental number line or if they needed to acquire it over their life (Cammaerts \& Cammaerts, 2020b).

Here below we recall what is known about the notion of zero in humans and animals, and report the available information on the origin and/or the acquisition of such a notion.

The notion of zero is lately acquired by humans in their life. For instance, 3-year-old children have already a correct notion of small integer amounts, but not yet that of zero as a null quantity (Bialystok \& Codd, 2000). By the time they are 4 years old, their understanding of zero as the absence of something, a null quantity, becomes as good as their understanding of whole numbers of items (Bialystok \& Codd, 2000). Some children begin then to include a non-quantitative representation of nothing into their mental number line, as shown by distance effect with empty sets (Merrit \& Brannon, 2013). The cardinality knowledge of zero and of small numbers in infants 4 to 5 years old appears to develop independently from one another, but to be associated with their language skills (Pixner, Dresen, \& Moeller, 2018). At the age of five, children's strategies begin to change from analogue to symbolic notations (Bialystok \& Codd, 2000). From about the age of seven, most children begin to conceive that zero is a quantity in a series of integers and understand an elementary algebraic use of the number 0 (Wellman \& Miller, 1986). At this age of seven and although they position the zero as a quantity less than 1, they still have difficulties in understanding the concept of quantities corresponding to fractions, e.g. a half or a quarter, and thus to position such quantities between 0 and 1 (Bialystok \& Codd, 2000).

Among vertebrates, some monkeys and birds have been proved to have the notion of zero. The chimpanzee (Pan troglodytes) could use numerical symbols for numbers including the zero in both cardinal and ordinal context, placing the zero near or at the lower end of a continuous numerical scale, however often confusing it with 1. In fact, this monkey has a concrete and not an abstract concept of zero (Biro \& Matsuzawa, 2001). Rhesus monkeys 
(Macaca mulatta) treat empty sets as precursors of zero in a numerical continuum (Merritt, Rugani, \& Brannon, 2009). The mental notion of zero in the grey parrot (Psittacus erithacus) is that of 'nothing', without denoting a specific numerosity (Pepperberg \& Gordon, 2005; Pepperberg, 2006b).

As for the invertebrates, honey bees (Apis mellifera) have a concrete notion of zero, as inferred from their behavior faced with an empty cue among other cues bearing a given number of elements (Howard, Avarguès-Weber, Garcia, Greentree, \& Dyer, 2018). We may infer that these insects also possess the notion of zero corresponding to the absence of a cue, since they present numerosity abilities of high level, performing simple arithmetic operations on numbers of elements by learning to use symbolic representations (Howard, Avarguès-Weber, Garcia, Greentree, \& Dyer, 2019).

Nieder (2016) pictured the acquisition of the notion of zero through four main stages: zero corresponds to a behavioral resting state due to absence of stimulus, zero corresponds to a meaningful category, but without a quantitative relevance (such as a blank space in a numbering system), zero has a quantitative meaning, that of a null or empty set at the low end of a number line and finally, zero is a particular number, with a given symbol, in a system enabling abstract mental operations. On the basis of our previous observations on the ant M. sabuleti (see references here above), we can presume that workers of this species have a concrete notion of zero corresponding to the second or the third step of this staging.

As far as we know, no work has been made about the acquisition of the notion of zero by young animals. This gap makes the present work still more interesting. In this work, we inevitably used methods and materials similar to those used for revealing the ants' notion of zero.

\section{Materials and Methods}

\subsection{Collection and Maintenance of Ants}

The experiments were conducted on four small colonies made of the younger workers removed from a large colony collected in September 2019 in an abandoned quarry located at Olloy/Viroin (Ardenne, Belgium). That colony was living in grass, ground and between small stones, and contained more than 2,000 workers. It was divided in 10 smaller colonies maintained in the laboratory and from which the young workers were removed in order to obtained the four experimental colonies (labeled A to D) required for the present work. Each of these four colonies was maintained in a semi-transparent tube (diam: $1 \mathrm{~cm}$, length: $7.5 \mathrm{~cm}$ ), half-filled with water, a cotton plug separating the ants from the water. Each tube was set in a tray $(30 \mathrm{~cm} \times 15 \mathrm{~cm} \times 4 \mathrm{~cm})$ serving as foraging area, the borders of which having been slightly covered with talc to prevent ants from escaping (Figure 1). The ants' food consisted in a solution of honey in milk $(20 \%, \mathrm{~V} / \mathrm{V})$ delivered in cotton plugged tubes (diam: $0.5 \mathrm{~cm}$, length: $2.5 \mathrm{~cm}$ ) permanently set in the trays and renewed every seven days (Figure 1). The ants' training also occurred in these trays (Figure 2, left part). In the laboratory, the lighting used while caring of the ants and experimenting on them was produced by a Philips TLD $30 \mathrm{~W} / 33$ white light tube and had an intensity of 330lux. During other time periods, i.e. while not working on ants, the lighting was that issued from a window, providing natural light and dark periods ( $c a 8: 16 \mathrm{~h}$ periods). The temperature was maintained at $20^{\circ} \pm 1^{\circ} \mathrm{C}$, the ambient humidity at $c a 80 \%$, and the electromagnetic field equaled $2 \mu \mathrm{W} / \mathrm{m}^{2}$. Such environmental conditions are optimum for the species.

\subsection{Ants' Training}

The ants were trained on their foraging area, the cue to memorize (i.e. the correct cue) being deposited near the tube filled of food. Another cue was deposited far from the food (Figure 2, left part), or near an empty food tube plugged with cotton (Figure 5) (see also photos in Figures 6, 7). These cues, described here below, differed according to the experiment performed and to the used colony. The ants were trained during 1 or 2 days, and during each of these days, the ants sighted in the vicinity of the two presented cues were counted four times over the day. The mean of these counts was established for each day (Tables 1 and 2, column 2), and the global mean (i.e. that for the two days) obtained for each experiment is given in the subsection 'Results'.

\subsection{Ants' Testing}

After one and/or two training days, the ants of the experimented colonies were tested in a separate tray $(15 \mathrm{~cm} \mathrm{x}$ $7 \mathrm{~cm} \times 4.5 \mathrm{~cm}$ ) the borders of which having been slightly covered with talc and into which the kind of cues used to train the ants had been set (Figure 2, right part). The cues devoted to test were identical to those devoted to training but were new, never used. Half of the tests were made with the cues inversely located ( $180^{\circ}$ rotated) in order to avoid any effect of oriented lighting on the ants' choice. During each testing session, the ants approaching the two cues at a distance of maximally $2 \mathrm{~cm}$ were counted twenty times over ten experimental minutes, and the mean of each of these counts was calculated (Tables 1 and 2, column 3). Note that one kind of used cue was 'nothing'; in this case, a thin pencil drawn point indicated the position of the 'nothing'. 


\subsection{Cues Presented to the Ants}

The cues were either a black circle (diam: $0.5 \mathrm{~mm}$ ) drawn in a $2 \mathrm{~cm} \times 2 \mathrm{~cm}$ square paper, or such a piece of white paper with no drawing on it, or simply no any cue or other element (= 'nothing'). The piece of paper with a drawn black circle or without any drawing was tied on the front face of a $2 \mathrm{~cm}$ x $2 \mathrm{~cm}$ stand made of Steinbach paper ${ }^{\circledR}$ which was vertically maintained thanks to a prolonged basis $[2 \times(1 \mathrm{~cm} \times 0.5 \mathrm{~cm})]$, duly orthogonally folded (Figure 3, upper part).

The cues presented to the ants during the training, as well as those, identical, but new presented during the testing sessions, are shown in Figure 3, lower part and in Figure 4.

During a first series of experiments aiming to know if young ants possess the notion of zero, colony A received a black circle near the food and a white piece of paper far from the food. Colony B was provided with a white piece of paper near the food and a black circle far from the food. Colony $\mathrm{C}$ was furnished with a black circle near the food and 'nothing' far from the food (a thin pencil drawn point indicating the latter location). Colony D had 'nothing' near the food and a black circle far from the food.

During a second series of experiments, the aim of which was to learn the notion of zero to the ants, the ants were firstly provided with a filled and an empty food tube set side by side at day 1, and set far from one another at day 2 . After that, the ants of colonies A and B were trained, during day 3, to an empty stand set near the food and to a stand with a black circle set far from food, but placed near an empty tube, and were tested in front of these two cues on day 4. On day 5, they were trained to an empty stand set near the food and to only a stand with a black circle set far from the food, and were tested in front of these two cues on day 6 . In the same way, the ants of colonies $\mathrm{C}$ and D were similarly trained, during day 3, to 'nothing' near the food and to a stand with a black circle set far from food, but placed near an empty tube, and were tested in front of these two cues on day 4. On day 5, they were trained to 'nothing' near the food and to only a stand with a black circle set far from the food, and were tested in front of these two cues on day 6.

During each testing session, the ants approaching each cue were counted twenty times over ten minutes and the mean value corresponding to each kind of cue was calculated (Table 1, third column).

\subsection{Statistical Analysis}

Data recorded during training required so statistical analysis.

Data recorded during testing were analyzed as follows. For each experiment, the twenty chronologically obtained numbers of ants counted near each stand were summed by four over the twenty counts, and the five sums obtained for each kind of cue were compared to one another using the non-parametric test of Wilcoxon (Siegel \& Castellan, 1989). The level of probability was set at 0.05 .
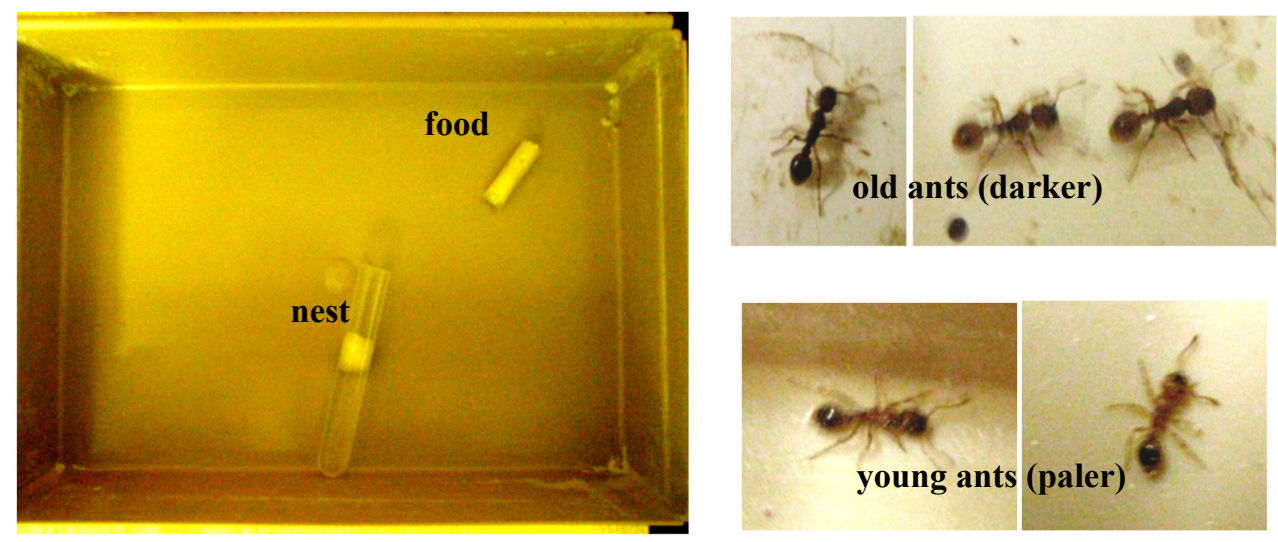

Figure 1. The young ants used and their maintenance

The ants used were the young ones collected from a large colony. They were paler than their older nestmates and were maintained in small nest tubes placed in small trays. A solution of honey in milk was provided as food. 


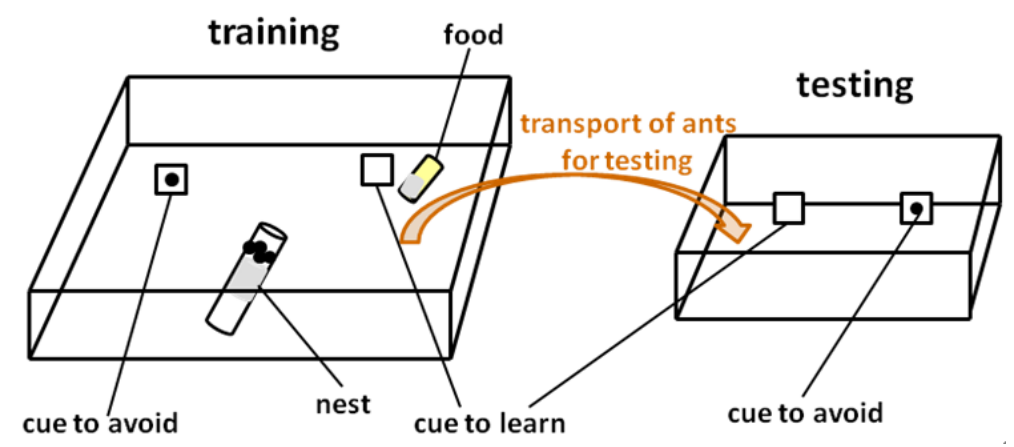

Figure 2. Experimental design used for training and testing the ants

The ants were trained on their foraging area, the cue to memorize being set near the food. They were tested in a separate tray containing the cue to memorize and the other one. Half of the tests were made with the cue to memorize on the left, half of the tests with that cue set on the right. The cues are shown in Figures 3 and 4.

\section{Results}

\subsection{Synopsis}

We successively relate the results of a first series of experiments, the aim of which being to know if young ants have the notion of zero. Results are given in Table 1; photos are shown in Figure 5. We first relate the experiments performed using a stand with a black circle and an empty stand as cues, and then those conducted using a stand with a black circle and nothing. We then relate the results of a second series of experiments the aim of which being to learn the notion of zero to the young ants. Results are given in Table 2; photos are shown in Figure 6. Again, we first report the results of the experiments made using a black circle and a white paper as cues, then those made using a black circle and nothing.

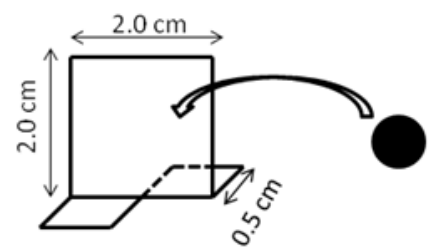

First series of experiments: the ants were trained during three days and tested twice using a black circle and a white paper or 'nothing'. colonies; days training to a cue set near food vs far from it

\section{testing in front of the cues previously set near food and that set far from the food}
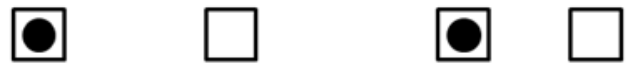

or
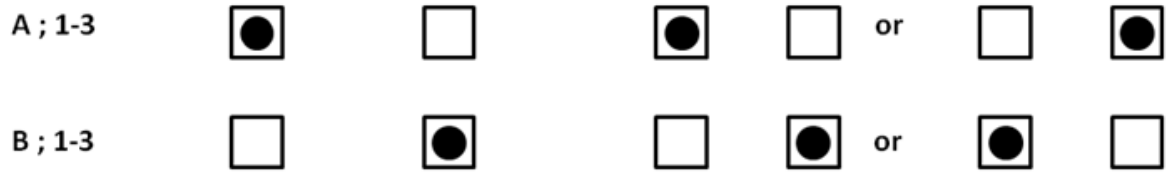

$$
\text { C ; 1-3 }
$$

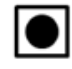

nothing

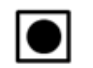

nothing or nothing

\section{$D$; 1-3 nothing}

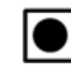

nothing

$\square$ or

$\square$ nothing

Figure 3. Cues used to train and test young ants in the course of the first series of experiments

The aim of these experiments was to examine if young ants detain the notion of zero, 'zero' being represented by an empty stand (a white paper) or by nothing. Each time, it was first checked if ants could acquire conditioning to a black circle (colonies A, C), then if ants could acquire conditioning to zero (colonies B, D). (Results in Table 1; photos in Figure 5). 
Second series of experiments: the ants were provided with a filled and an empty food tube, set aside each other on day 1 and set apart on day 2; they were trained on days 3 , then 5 and tested on days 4 , then 6 .

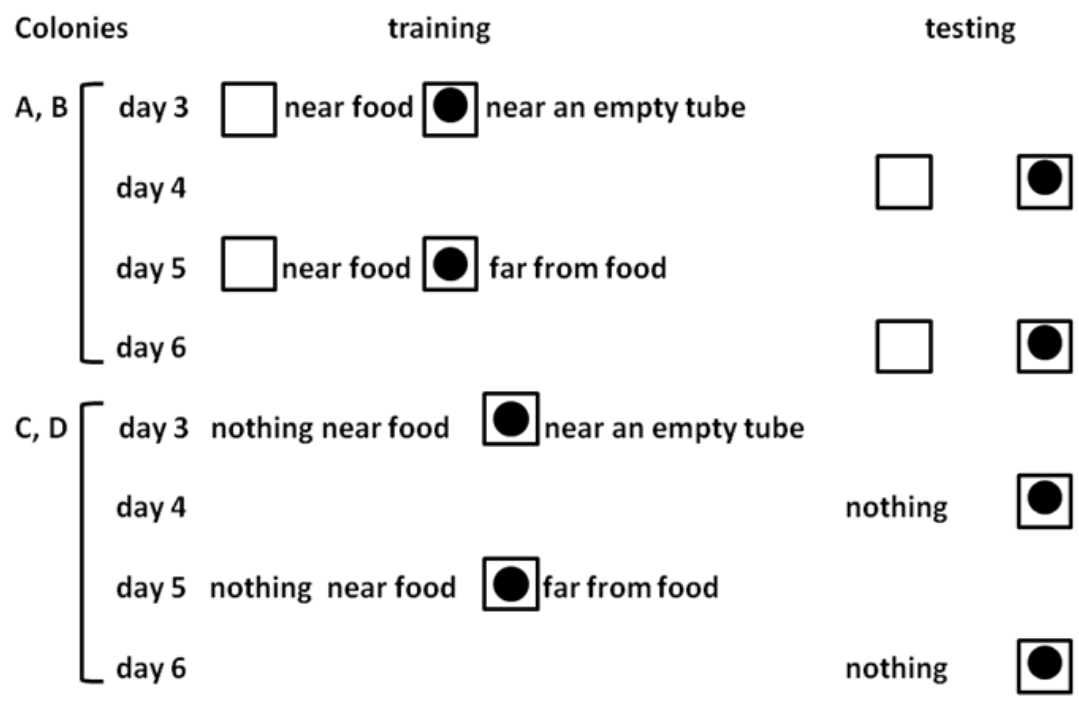

Figure 4. Cues used to train and test young ants in the course of the second series of experiments

The aim of these experiments was to learn the notion of zero to young ants, zero being represented by a white paper (colonies A and B) or by 'nothing' (colonies C and D). After having perceived a filled food tube as well as an empty food tube during two days (days 1 and 2) (this was not a training), the ants were trained to 'zero' (i.e. an empty stand for colonies A and B; nothing for colonies C and D) set near the food $v s$ a black circle set near an empty food tube (day 3) or far from the food (day 5). (Results in Table 2; photos in Figure 7).

\subsection{First Series of Experiments (Table 1, Figure 6)}

\subsubsection{Experiment I (Colony A); a Black Circle vs a White Paper}

During their training, meanly 1.7 ants were present at any time in the vicinity of the two presented cues; they could thus see and memorize them. When tested after two training days, as expected, these ants moved preferentially towards the black circle. Meanly, 3.6 ants were counted there while 1.2 ants were counted near the white paper. Summed by four over the twenty counts, the numbers of ants which approached the black circle were 14, 13, 14, 16, 15 , and which approached the white paper were $5,5,4,5,5$. These two series of five values statistically differed ( $\mathrm{N}$ $=5, \mathrm{~T}=15, \mathrm{P}=0.031$ ). The young ants could thus be conditioned to a visual cue, i.e. a black circle, even if slightly responding to the white paper which should be avoided. Tested again after three training days in front of the two $180^{\circ}$ rotated cues, the same ants went again preferentially to the black circle, being meanly 3.3 in doing so, while meanly 0.9 ants went to the white paper. Summed by four, the numbers of ants counted near the black circle equaled $15,14,12,11,14$, and counted near the white paper, they equaled $5,0,4,4,4$. These two series of values statistically differed $(\mathrm{N}=5, \mathrm{~T}=15, \mathrm{P}=0.031)$. The young ants could thus be conditioned to a black circle. Their conditioning score equaled $80.4 \%$ and $79.5 \%$ after two and three training days respectively, what was their maximum score, and was a valuable significant conditioning score.

\subsubsection{Experiment II (Colony B); a White Paper vs a Black Circle}

During their training, the young ants of colony B could sufficiently perceived the two presented cues, being meanly 3.2 at any time in the vicinity of these cues. Tested after two training days, the young ants did not preferentially go to the white paper. Meanly, 0.8 ants were counted there while 0.9 ants were counted near the black circle. Summed by four over the twenty counts, the numbers of ants approaching the white paper were 1, 3, 2, 3,6 , and of ants approaching the black circle were $3,3,3,3,6$. These two series of values did not statistically differ $(\mathrm{N}=2, \mathrm{NS})$. Thus, the young ants could not acquire conditioning to a white paper in the course of two training days. Tested again after one more training day in front of the same but $180^{\circ}$ rotated cues, the young ants once more did not go preferentially to the white paper. Meanly, 1.7 ants went to the white paper and 1.6 ones went to the black circle. Summed by four over the twenty counts, the numbers of ants sighted near the white paper were 10, 5, 6, 7, 5, and sighted near the black circle were 11, 5, 5, 6, 5. Again, these two series of values did not significantly differ ( $\mathrm{N}$ 
$=3$, NS). It could thus be concluded that, trained to a white paper set near their food, young ants failed in acquiring conditioning. They did not perceive a white paper (= a paper with nothing on it) as a valuable visual cue. For them, 'nothing' had no signification.

Table 1. Results of a first series of experiments allowing examining if young ants have the notion of zero

\begin{tabular}{|c|c|c|c|c|c|}
\hline \multirow[t]{2}{*}{ Colony } & \multirow{2}{*}{$\begin{array}{l}\text { Cue near } v s \text { far } \\
\text { from food }\end{array}$} & \multirow[t]{2}{*}{ Day } & \multirow{2}{*}{$\begin{array}{l}\text { Training: } n^{\circ} \text { of ants } \\
\text { around the cues }\end{array}$} & \multicolumn{2}{|c|}{ Testing: $n^{\circ}$ of ants approaching the cue } \\
\hline & & & & associated to food & not associated to food \\
\hline \multirow[t]{2}{*}{ A } & ○ vs $\square$ & day 2 & 1.8 & $3.6(72)$ & $1.2(24)$ \\
\hline & & day 3 & 1.5 & $3.3(66)$ & $0.9(17)$ \\
\hline \multirow[t]{2}{*}{ B } & $\square$ vs $\square$ & day 2 & 3.5 & $0.8(15)$ & $0.9(18)$ \\
\hline & & day 3 & 2.8 & $1.7(33)$ & $1.6(32)$ \\
\hline \multirow[t]{2}{*}{$\mathrm{C}$} & - vs. & day 2 & 2.5 & $2.7(53)$ & $0.6(12)$ \\
\hline & & day 3 & 3.5 & $1.8(36)$ & $0.6(11)$ \\
\hline \multirow[t]{2}{*}{$\mathrm{D}$} & vs $\mathbf{0}$ & day 2 & 3.5 & $1.8(35)$ & $2.5(49)$ \\
\hline & & day 3 & 4.0 & $1.4(28)$ & $1.8(36)$ \\
\hline
\end{tabular}

Trained during three days, and tested at days 2 and 3, ants appeared to be able to acquire conditioning to a black circle set near their food (colonies A and C) but not to a white paper or to 'nothing' set near the food (colonies B and D). They were thus able to acquire conditioning to a concrete cue but not to a white paper or to nothing. They did not perceive the absence of cue as an element. The table gives the mean numbers of ants and, into brackets, the numbers of counted ants. Details are given in the text; photos are shown in Figure 5.

\subsubsection{Experiment III (Colony C); a Black Circle vs Nothing}

During their training, the young ants of colony $\mathrm{C}$ could perceive the cue presented near the food as well as the absence of any cue far from the food, being indeed meanly 3.0 on these areas, at any time. Tested after two training days, these ants went, as expected, essentially to the black circle, ignoring the place where no cue was set. Meanly, 2.7 ants were counted in the vicinity of the black circles and 0.6 ones in the vicinity of the place where there was no cue. Summed by four over the twenty counts, the numbers of ants having approached the black circle were 12,11 , $12,10,8$, and having approached the place with no cue were $2,3,2,3,2$. The two series statistically differed $(\mathrm{N}=$ $5, \mathrm{~T}=15, \mathrm{P}=0.031$ ). The young ants could thus acquire conditioning to the black circle in the course of two training days. Tested again after one more training day, in front of the same but $180^{\circ}$ rotated cues, these ants went again mostly to the black circle and far less to the place where no cue was present. Meanly, 1.8 ants were sighted near the black circle and 0.6 ants were sighted where there was no cue. Summed by four over the twenty counts, the numbers of ants reacting to the black circle were $10,5,8,6,7$, and those of ants moving where there was no cue were $2,1,2,3,3$. These two series of values statistically differed $(\mathrm{N}=5, \mathrm{~T}=15, \mathrm{P}=0.031)$. The young ants have thus acquired valuable conditioning to a black circle. It could be concluded that young ants could associate a black circle to the presence of food, reaching a conditioning score of $81.5 \%$ and $76.6 \%$ after two and three training days, these scores being their maximum and valuable score.

\subsubsection{Experiment IV (Colony D); Nothing vs a Black Circle}

During their training, the ants were sufficiently present near the black circle set far from the food and near the food where no cue was present for memorizing these two cues and their location. Indeed, they were meanly 3.8 there at any time. Tested after two training days, these young ants did not statistically go preferentially towards the place where there was no cue. Meanly 1.8 ants were counted on this area while 2.5 ones were counted near the black circle. Summed by four over the twenty counts, the numbers of ants which approached the place with no cue were $6,2,12,3,8$, and which approached the black circle were $10,11,12,8,8$. These two series of five values, though somewhat differing from one another in favor of the black circle, were not significantly different $(\mathrm{N}=3, \mathrm{NS})$. Thus, the young ants could not acquire conditioning when the element they should associate with food was an absence of element, was 'nothing'. Tested again after one more training day, in front of the same but $180^{\circ}$ rotated two cues, the young ants again did not mostly go to the place where no cue was present, but went slightly more to the black circle. Meanly, 1.4 ants were counted on the place where there was no cue and 1.8 ones were counted near the black circle. Summed by four over the twenty counts, the numbers of ants sighted at the place where no cue was present were $6,8,7,4,3$, and those sighted near the black circle were 10,7,7,6,5. These two series of five values differed in favor of the series relative to the black circle although not significantly $(\mathrm{N}=4, \mathrm{~T}=+9,-1, \mathrm{P}=0.125)$. 
Consequently, the young ants did not consider 'nothing' as being a true element; they thus did not detain the notion of zero.

Table 2. Results of a second series of experiments, the aim of which being to learn the notion of zero to the ants

\begin{tabular}{|c|c|c|c|c|c|c|}
\hline \multirow[t]{2}{*}{ Colonies } & \multirow{2}{*}{$\begin{array}{l}\text { Cues and their relation with } \\
\text { food }\end{array}$} & \multirow[t]{2}{*}{ Day } & \multirow{2}{*}{\multicolumn{2}{|c|}{$\begin{array}{c}\text { Training: } \mathrm{n}^{\circ} \text { of ants } \\
\text { near the cues }\end{array}$}} & \multicolumn{2}{|c|}{ Testing: $\mathrm{n}^{\circ}$ of ants near the cue } \\
\hline & & & & & associated to food & associated to no food \\
\hline \multirow[t]{6}{*}{ A, B } & Presentation of a filled and an & 1 & 2.2 & 2.8 & & \\
\hline & empty food tube & 2 & 1.5 & 2.0 & & \\
\hline & $\square+$ food $\square+$ empty tube & 3 & 1.5 & 2.3 & & \\
\hline & & 4 & & & $2.3(46), 3.4(68)$ & $0.6(11), 0.8(15)$ \\
\hline & $\square+$ food $\square$ far from food & 5 & 1.8 & 4.3 & & \\
\hline & & 6 & & & $1.6(31), 2.5(49)$ & $0.6(11), 0.9(17)$ \\
\hline \multirow[t]{6}{*}{ C, D } & Presentation of a filled and an & 1 & 2.2 & 2.8 & & \\
\hline & empty food tube & 2 & 1.5 & 2.0 & & \\
\hline & nothing+food $\bigcirc$ tempty tube & 3 & 1.5 & 4.5 & & \\
\hline & & 4 & & & $2.5(50), 1.9(37)$ & $0.5(10), 0.5(10)$ \\
\hline & nothing+food $\square$ far from food & 5 & 3.3 & 3.8 & & \\
\hline & & 6 & & & $2.9(57), 2.6(52)$ & $1.0(19), 0.7(13)$ \\
\hline
\end{tabular}

After having been provided with a filled and an empty food tube, young ants were trained to a white paper or to 'nothing' $v s$ a black circle. When tested, they responded mostly to the white paper or to the 'nothing', having thus acquired a concrete notion of zero. Numbers not in brackets are means and numbers in brackets are those of counted ants. Details and statistics are given in the text; photos are shown in Figures 5 and 7.

\subsection{Second Series of Experiments (Table 2, Figure 7)}

3.3.1 Experiment 1 (Colonies A, B); a Filled and an Empty Food Tube, Then Conditioning to a White Paper vs a Black Circle

While being provided with a filled and an empty food tube, the ants of these two colonies came near these two tubes, perceiving thus their difference. They were meanly 2.1 in doing so at any time. While trained to a stand bearing a white paper set near the food and to a stand bearing a black circle set apart near an empty food tube, they were again somewhat present on these areas, being meanly 1.6 there at any time. Tested on day 4 in front of these two cues, the ants of each colony unexpectedly went immediately towards the white paper and went on going mostly to that cue over the ten experimental minutes. In total, 46 and 68 ants of colony A and B respectively were sighted near the white paper, while 11 and 15 ants respectively of these two colonies were sighted near the black circle. The proportion of correct responses equaled thus $80.3 \%$. Summed by four over the twenty counts, the numbers of ants of the two colonies having approached the white paper were $23,25,27,22,17$, and of ants having approached the black circle were $1,6,9,7,3$. These two series of values statistically differed $(\mathrm{N}=5, \mathrm{~T}=15, \mathrm{P}=$ 0.031 ). The ants have thus learned that a white paper, i.e. a paper with nothing on it, can be a cue to which it may be useful to react. However, for this test, the ants had been trained with the black circle set near an empty food tube. The ants' correct response was consequently only a first step in the acquisition of the notion of zero. During the following day, the ants were trained again to a white paper set near the food vs a black circle this time set near nothing (i.e. no longer near an empty food tube). They were meanly 3.1 in moving or being present on these areas and could thus perceive the two presented cues and their location. Tested one day later, the ants of the two colonies went preferentially to the white paper, though doing so somewhat less than during the previous test. Meanly, 80 ants were counted in front of the white paper and 28 ants were counted in front of the black circle. Their proportion of correct responses equaled thus $74.1 \%$. Summed by four over the twenty counts, the numbers of ants reacting to the white paper were $22,23,12,10,13$, and of ants reacting to the black circle were $9,11,1,3,4$. These two series of five values significantly differed $(\mathrm{N}=5, \mathrm{~T}=15, \mathrm{P}=0.031)$. Consequently, the experimented young ants preferentially reacted to a white paper and not to a black circle, perceiving the white paper as a true cue even if there was no drawing, no element on it. They thus acquired a concrete notion of 'nothing' of 'zero'. As a white paper approached the notion of zero, but was not entirely such a notion, the following experiment examined what occurred when no any cue (i.e. nothing) was used instead of a white paper. 

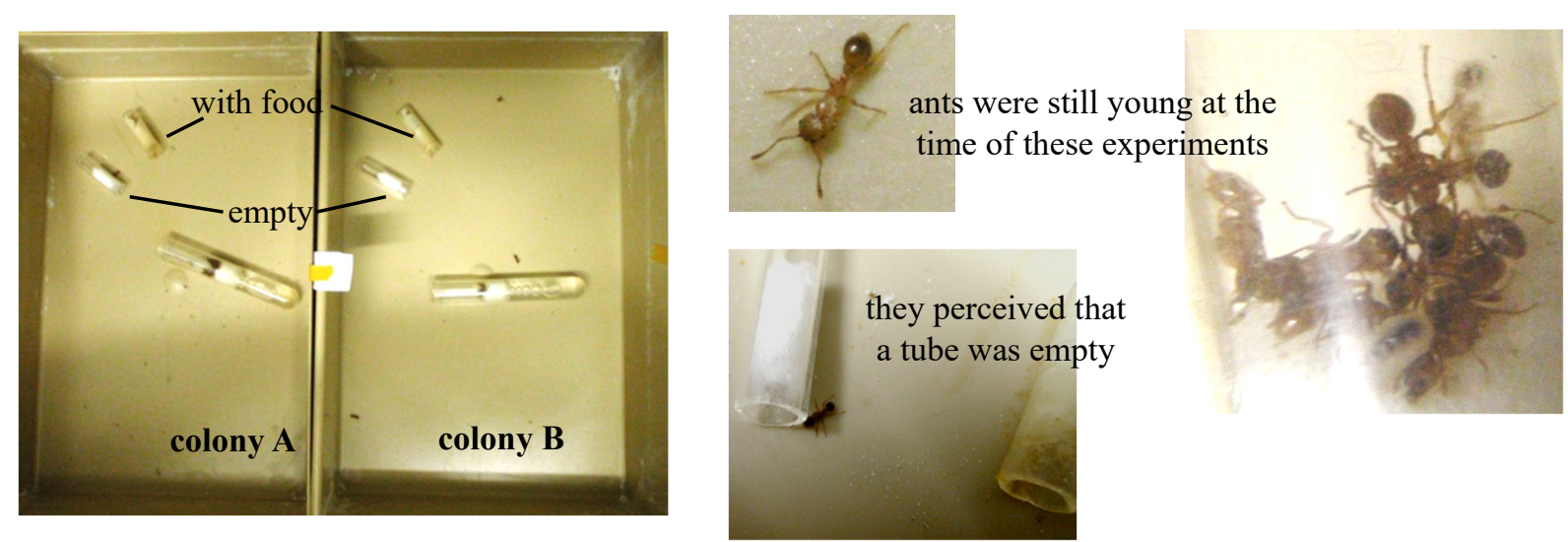

Figure 5. Preparation of the second series of experiments made for tempting learning the notion of zero to ants

3.3.2 Experiment 2 (Colonies C, D); a Filled and an Empty Food Tube, Then Conditioning to 'Nothing' vs a Black Circle

The young ants of the two colonies were provided with a filled and an empty food tube during two days. They were meanly 2.1 in being at any time in the vicinity of these tubes and could thus perceive their characteristics (i.e. the lack of food in one of the tubes). They were then trained to 'nothing' near their food and to a black circle near an empty tube, and were at that time meanly 3.0 all around these two locations. When tested the day after, these young ants preferentially went to the place where there was nothing and far less to the black circle. In total 87 ants of the two colonies were counted at the place where no cue was present and 20 ants were counted near the black circle. Thus, the ants correctly responded with a score of $81.5 \%$. Summed by four over the twenty counts, the numbers of ants sighted at the place where no cue was present were $25,20,17,13,12$, and those of ants sighted near the black circle were $5,4,3,4,4$. These two series of values significantly differed $(\mathrm{N}=5, \mathrm{~T}=15, \mathrm{P}=0.031)$, the young ants having thus perceived 'nothing', 'no cue' as something to be taken into account. They have thus acquired a basic notion of zero. During this experiment, the ants were trained with the back circle set near an empty tube, what helped them avoiding the black circle when being tested. For checking their learning of the notion of zero, the ants were then trained to 'nothing' near their food $v s$ a black circle set far from food. During this training, the ants were meanly 3.6 in being present on their foraging area, perceiving thus their food with 'nothing' aside and a black circle far from food. Tested the day after, these young ants went more to the place where there was no cue than to the black circle. In total, 109 ants were counted on the former area and 32 ones on the latter place, the ants presenting thus a conditioning score of $77.3 \%$. Summed by four over the twenty counts, the numbers of ants sighted at the place where no cue was present were 29,27, 22, 16, 15, and of ants sighted near the black circle were $8,8,9,4,3$. These two series of numbers significantly differed $(\mathrm{N}=5, \mathrm{~T}=15, \mathrm{P}=0.031)$. The young ants have thus correctly perceived the black circle as the wrong cue, and the absence of cue, the 'nothing' as the correct element to which they should respond. Even if responding somewhat less than in the previous test, the ants have thus acquired, at the issue of two training days, a basic and concrete notion of nothing or zero. 


\section{Training}
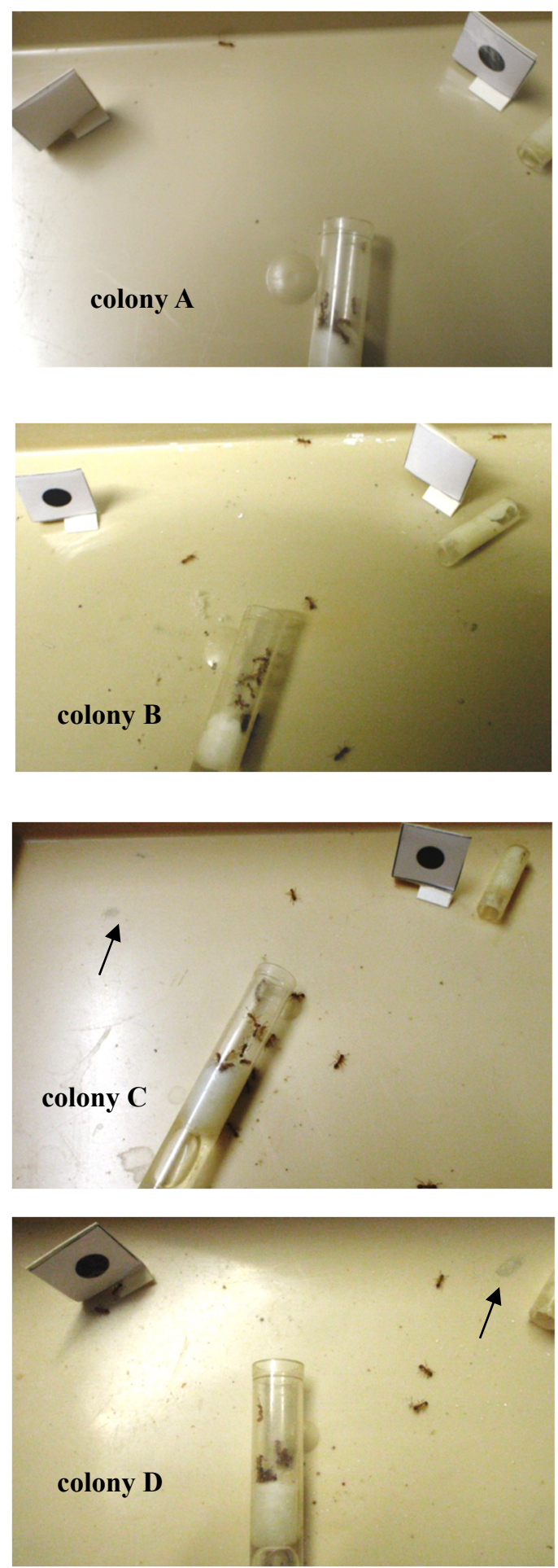

Testing
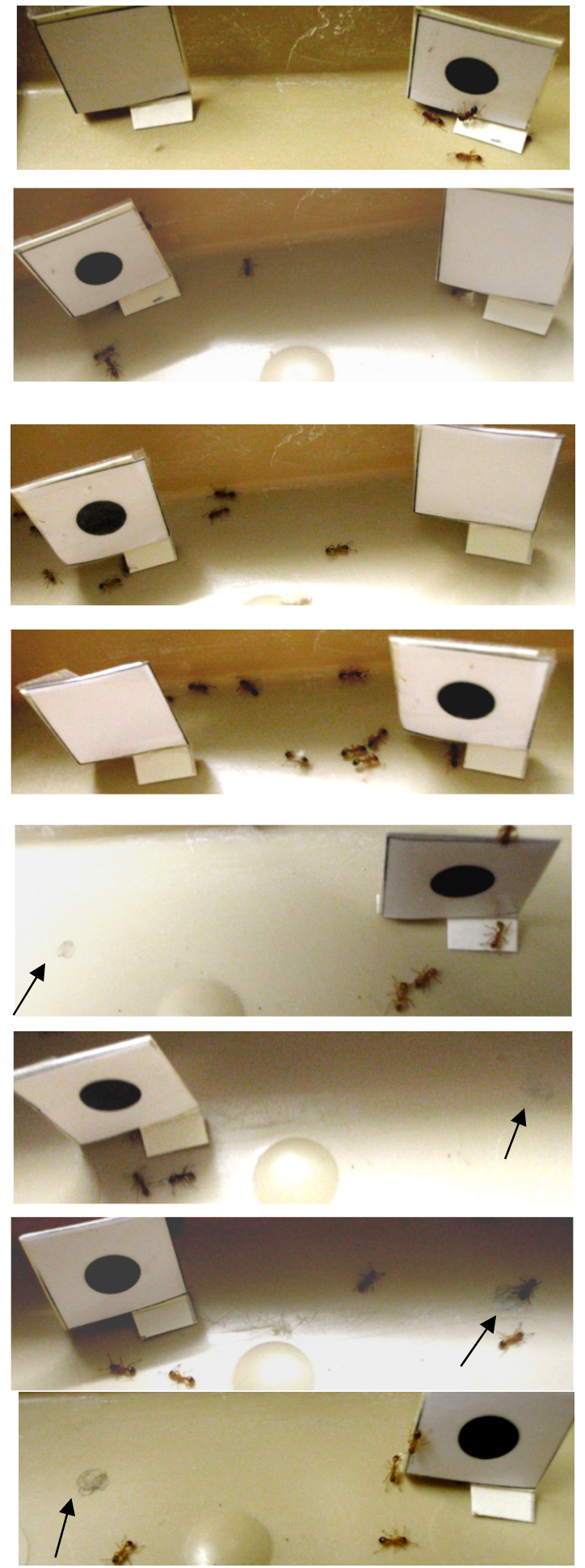

Figure 6. Some views of the experiments made to know if young ants have the notion of zero

Young ants of colonies $\mathrm{A}$ and $\mathrm{C}$ were conditioned to a black circle in order to check if they could acquire conditioning, what the case was. Young ants of colonies B and D were tried to be conditioned to 'zero' represented by a white paper or by 'nothing' (its place being marked by a pencil drawn point and here indicated by an arrow), and obviously they did not succeed. Each test was made with the correct cue (that set near the food during training) set on the left, then on the right. 


\section{Training}
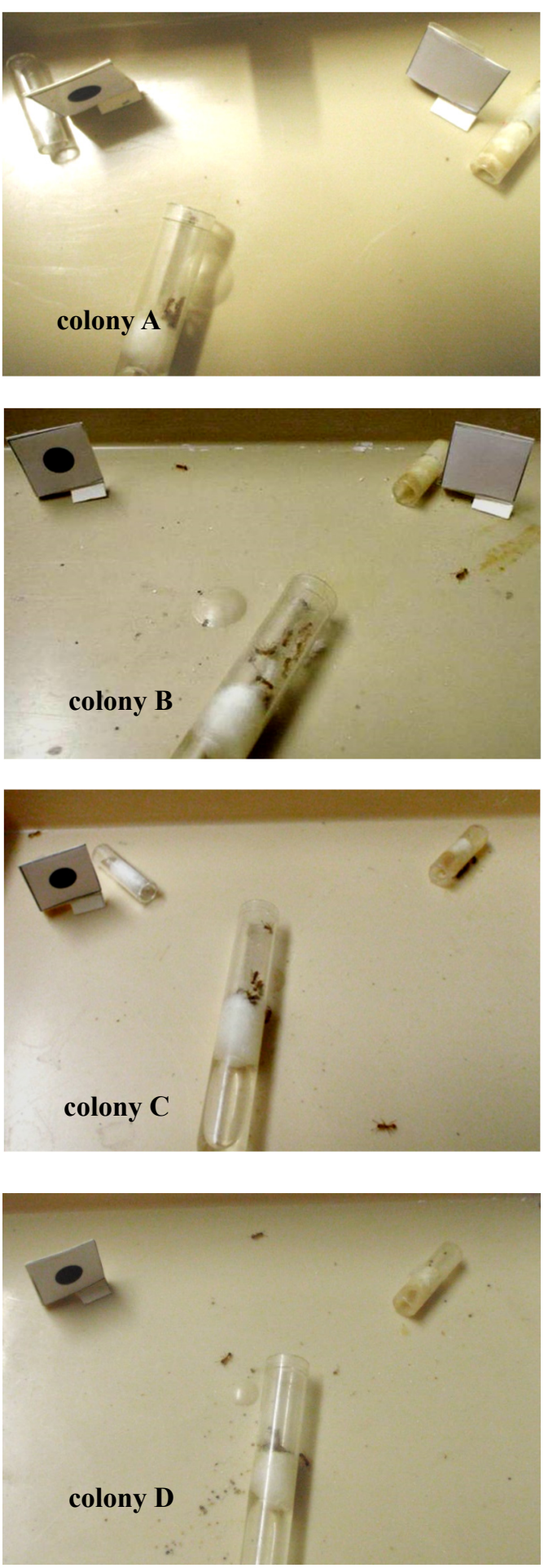

\section{Testing}
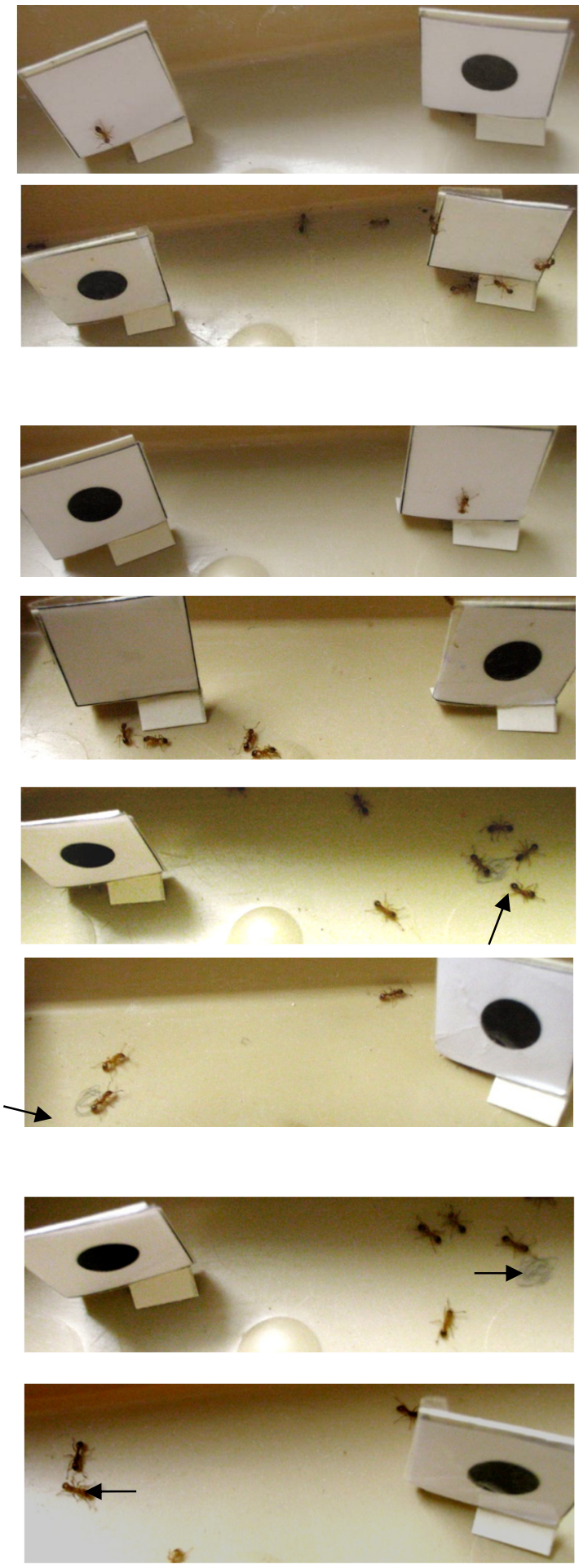

Figure 7. Views of the experiments conducted for trying to learn the notion of zero to young ants

After having been provided with a filled and an empty food tube, young ants were trained to a white paper (colonies A, B) or to 'nothing' (colonies C, D) vs a black circle in the presence (photos of colonies A, C), then in the absence (photos of colonies B, D) of an empty food tube. When tested, they responded essentially to the white paper or to 'nothing', what showed that they learned what was 'nothing', i.e. the absence of an element. Each test was made with the correct cue (that placed near the food during training) set on the left, then on the right. 


\section{Discussion, Conclusion}

Knowing that the workers of the ant M. sabuleti have a concrete notion of zero, we aimed to know how they acquire such a notion, i.e. do they detain it natively or do they acquire it through experiences. Working on young ants and using operant conditioning to a white paper or to 'nothing' vs a concrete cue, we showed firstly that young ants of this species did not detain the notion of zero, and secondly that they can acquire this notion through experiences, i.e. when confronted to a filled and to an empty food tube. In contrast, these young ants early possess a left to right oriented number line (Cammaerts \& Cammaerts, 2020b).

Since in ants, contrary to their notion of concrete amounts, the notion of zero, of 'nothing' has to be learned through experiences, not all the ants of a colony may understand that an empty cue or its absence represents a true element consisting in 'nothing'. Consequently, the ants' score in discriminating 1 from 2 elements may be slightly higher than their score in discriminating zero from 1 element. Indeed, when studying the ants' notion of zero (Cammaerts \& Cammaerts, 2019a), we found a conditioning score of $82.5 \%$ for the ants' discrimination between 2 and 1 circles. When studying the ants' correct location of the zero (Cammaerts \& Cammaerts, 2019c), we found a conditioning score of $83.3 \%$ for the discrimination of 2 vs 1 elements (mean ants' response: $4.0 v s$ 0.8), and a conditioning score of $82.6 \%$ for the discrimination of $1 v s 2$ elements (mean ants' response: $3.8 v s$ 0.8). When studying the ants' arrangement of numbers on their number line (Cammaerts \& Cammaerts, 2020a), we found a conditioning score of $83.4 \%$ for the ants' discrimination of 1 vs 2 elements, during their first 48 training hours. These previous results are in agreement with one another, and the mean ants' discrimination between 1 and 2 elements equals $82.9 \%$. While studying if foragers (about 2 years old) detain the notion of zero (Cammaerts \& Cammaerts, 2019a), we found, after 48 training hours, a conditioning score of $71.3 \%$ for the discrimination of a white paper $v s$ a black circle, and a conditioning score of $76.7 \%$ for the discrimination of a black circle $v s$ a white paper, as well as conditioning scores of $73.5 \%$ and $78.7 \%$ for the discrimination of a black square $v s$ 'nothing', and conditioning scores of $59.8 \%$ and $66.7 \%$ for the discrimination of 'nothing' vs a black square. All these experimental results are in agreement with one another, and allow concluding that foragers present a conditioning score of about $71.1 \%$ when asked to discriminate 1 element from 0 element, a lower score than when discriminating 1 from 2 elements ( $82.9 \%$ : see here above).

Interestingly, Brysbaert (1995) found that adult humans, although having a logarithmic mental representation of numbers on their number line, take more time to read the numeral 0 than expected on the basis of this compressive representation, what should indicate that a different processing exists for zero and for integers. Consequently, this would suggest the possibility that zero is not included in the humans' number line. However, when tested through the size congruity effect, zero was shown to be effectively perceived as being the smallest quantity located on the humans' mental number line (Pinhas \& Tzelgov, 2012).

Having a number scale appears to be natively or very early detained, not only in ants (Cammaerts \& Cammaerts, 2020b), but also in the few other animals which have been studied as for this topic, such as chicks (Rugani, Vallortigara, Priftis, \& Regolin, 2015) and rhesus monkeys (Hauser, Carey \& Hauser, 2000). Humans also appear to natively possess a mental number line as it has been shown in 7-months old infants (de Hevia, Girelli, Addabbo, \& Cassia, 2014) and even in neonates (de Hevia, Izard, Coubart, Spelke, \& Streri, 2014). On the contrary, humans acquire lately the notion of zero ( $c a$ at the age of four: Bialystok \& Codd, 2000) and do not learn representing it by a symbol before the age of about six (Wellman \& Miller, 1986). The notion of zero needs thus to be explained during childhood, and this is not always efficiently made (Wheeler \& Feghali, 1983).

It has been shown that rhesus monkeys (Merritt, Rugani, \& Brannon, 2009) and humans (Pinhas \& Tzelgov, 2012) locate the zero on a number line, and ordered it at the start of a numerical continuum. Concerning the ant species here studied, its workers locate the zero at the start of an increasing series of elements as well as at the end of a decreasing series of elements (Cammaerts \& Cammaerts, 2019c), and since these ants have a left to right oriented number line (Cammaerts \& Cammaerts, 2019d), it can be deduced that they locate the zero on the left, just at the beginning of their number line.

The acquisition of the notion of zero in animals seems to have not yet been examined. In the present study, we found that worker ants acquire the notion of zero through experiences. To learn them acquiring this notion, we here used an empty food tube representing 'nothing' in comparison with a tube filled with food. In nature, the ants could acquire the notion of zero when confronted to lack of food or of water, to the departure of the sexual individuals, to the death of a queen, etc... For canids or other animals living in groups, zero may be represented by the departure or the death of the pack leader. Each time, the sudden, brutal lack of an important, vital thing may give to the animal the notion of nothing (not necessary in the course of an 'insight behavior'). The acquisition of the notion of 
zero may thus occur at different moments of an individuals' life, potential differences appearing therefore between individuals and possibly between populations.

As bees have the notion of zero (Howard et al., 2018), it should be of interest to examine how they acquire this notion. However, this will not be easy since bees live inside of a hive, and stay in life only during $c a 24$ days, contrary to the Myrmica ants which can live during three years.

Squirrel monkeys (Saimiri sciureus) have been proved to be able to acquire a symbolic representation of numbers associated to amounts, including the number zero (Olthof, Iden, \& Roberts, 1997), but the ' 0 ' sign could have meant 'nothing' rather than a null quantity (Nieder, 2016). A grey parrot (Psittacus erithacus) was able to make simple additions using symbolic labels, but presented a limited understanding concerning the zero concept since it did not use 'none' as a specific number (Pepperberg, 2006). A chimpanzee (Pan troglodytes) was found to be able to use a numerical symbol for zero in cardinal and ordinal contexts, although not without training (i.e. not spontaneously), and it presented a lack of flexibility between these contexts (Biro \& Matsuzawa, 2001). From the age of four, human infants begin to understand the cardinal and ordinal properties of zero (Bialystok \& Codd, 2000; Merrit \& Brannon, 2013). Besides having the notion of zero (Howard et al., 2018), bees can learn to associate symbols to numbers (Howard et al., 2019). It should thus be examined if they can associate a symbol to the zero. Concerning ants, a next aim should be to examine, using operant conditioning experiments, their potential ability of associating numbers to symbols, including the zero, but such a research must be preceded by an investigation about the ants' potential ability in discriminating numbers independently to the shape, size, color, and location of the elements representing the numbers.

\section{Conflict of interests}

The authors declare that there is no conflict of interests regarding the publication of this paper.

\section{References}

Bialystok, E., \& Codd, J. (2000). Representing quantity beyond whole numbers: Some, none, and part. Canadian Journal of Experimental Psychology, 54(2), 117-128.

Biro, D., \& Matsuzawa, T. (2001). Use of numerical symbols by the chimpanzee (Pan troglodytes): Cardinals, ordinals, and the introduction of zero. Animal Cognition, 4(3-4), 193-199.

Brysbaert, M. (1995). Arabic number reading: On the nature of the numerical scale and the origin of phonological recording. Journal of Experimental Psychology: General, 124(4), 434-452.

Cammaerts, M.-C., \& Cammaerts, R. (2019a). Ants are at the first stage of the notion of zero. International Journal of Biology, 11(1), 54-65.

Cammaerts, M.-C., \& Cammaerts, R. (2019b). Ants correctly locate the zero in a continuous series of numbers. International Journal of Biology, 11(4), 16-25.

Cammaerts, M.-C., \& Cammaerts, R. (2019c). Ants' notion of zero through the perception of the absence of an odor. International Journal of Biology, 11(2), 1-12.

Cammaerts, M.-C., \& Cammaerts, R. (2019d). Left to right oriented number scaling in an ant. International Journal of Biology, 11(4), 67-79.

Cammaerts, R., \& Cammaerts, M.-C. (2020a). Ants' mental positioning of amounts on a number line. International Journal of Biology, 12(1), 30-45.

Cammaerts, M.-C., \& Cammaerts, R. (2020b). Young ants already possess a mental number line. International Journal of Biology, 12(2), 1-12.

De Hevia, M. D., Girelli, L., Addabbo, M., \& Cassia, V. M. (2014). Human infants' preference for left-to-right oriented increasing numerical sequences. PLoSONE, 9(5), e96412.

De Hevia, M. D., Izard, V., Coubart, A., Spelke, E. S., \& Streri, A. (2014). Representations of space, time, and number in neonates. PNAS, 111(13), 4809-4813.

Hauser, M. D., Carey, S., \& Hauser, H. B. (2000). Spontaneous number representation in semi-free-ranging rhesus monkeys. Proceedings of the Royal Society of London B: Biological Sciences, 267, 829-833.

Howard, S. R., Avarguès-Weber, A., Garcia, J. E., Greentree, A. D., \& Dyer, A. G. (2018). Numerical ordering of zero in honey bees. Science, 360(6393), 1124-1126.

Howard, S. R., Avarguès-Weber, A., Garcia, J. E., Greentree, A. D., \& Dyer, A. G. (2019). Numerical cognition in honeybees enables addition and subtraction. Science Advances, 5, eaav0961. 
Merrit, D. J., \& Brannon, E. M. (2013). Nothing to it: Precursors to a zero concept in preschoolers. Behavioural Processes, 93, 91-97.

Merrit, D. J., Rugani, R., \& Brannon, E. M. (2009). Empty sets as part of the numerical continuum: Conceptual precursors to the zero concept in rhesus monkeys. Journal of Experimental Psychology: General, 138, 258-269.

Nieder, A. (2016). Representing something out of nothing: The dawning of zero. Trends in Cognitive Sciences, 20(11), 830-842.

Olthof, A., Iden, C. M., \& Roberts, W. A. (1997). Judgments of ordinality and summation of number symbols by squirrel monkeys (Saimiri sciureus). Journal of Experimental Psychology: Animal Behavior Processes, 23, 325-339.

Pepperberg, I. M. (2006). Grey parrot numerical competence: A review. Animal Cognition, 9, 377-391.

Pepperberg, I. M., \& Gordon, J. D. (2005). Number comprehension by a grey parrot (Psittacus erithacus), including a zero-like concept. Journal of Comparative Psychology, 119, 197-209.

Pinhas, M., \& Tzelgov, J. (2012). Expanding on the mental number line: Zero is perceived as the "smallest". Journal of Experimental Psychology: Learning, memory, and cognition, 38(5), 1187-1205.

Pixner, S., Dresen, V., \& Moeller, K. (2018). Differential development of children's understanding of the cardinality of small numbers and zero. Frontiers in Psychology, 9, 1636.

Rugani, R., Vallortigara, G., Priftis, K., \& Regolin, L. (2015). Number-space mapping in the newborn chick resembles humans' mental number line. Science, 347(6221), 534-536.

Siegel, S., \& Castellan, N. J. (1989). Nonparametric statistics for the behavioural sciences. Singapore: McGraw-Hill Book Company.

Wellman, H. M., \& Miller, K. F. (1986). Thinking about nothing: Development of concepts of zero. British Journal of Developmental Psychology, 4, 31-42.

Wheeler, M. M., \& Feghali, I. (1983). Much ado about nothing: Preservice elementary school teachers' concept of zero. Journal of Research in Mathematics Education, 14(3), 147-155.

\section{Copyrights}

Copyright for this article is retained by the author(s), with first publication rights granted to the journal.

This is an open-access article distributed under the terms and conditions of the Creative Commons Attribution license (http://creativecommons.org/licenses/by/4.0/). 